\title{
DIREITO SUBJETIVO E INTERESSE LEGÍTIMO ENTRE A NORMA E A PRAXIS URBANÍSTICA
}

\section{SUBJECTIVE LAW AND LEGITIMATE INTEREST BETWEEN THE URBAN STANDARD AND PRAXIS}

André R. C. Fontes*

Resumo: O Direito do Urbanismo pode ser definido como o conjunto de regras concernentes à afetação de espaço e sua disposição. Ele tem por objeto o urbanismo como realidade, como problema e como solução. É caracterizado por ser um direito empírico, complexo e patrimonial, no qual sobreleva a sua dimensão social. Este artigo trata das diferenças entre direito subjetivo e interesse legítimo na aplicação das normas urbanísticas.

Palavras-chave: Licenciamento. Administração. Construção.

Abstract: The Law of Urbanism can be defined as a set of rules regarding the use of space and its disposition. It aims at urbanism as a reality, as a problem and as a solution. An empirical, complex and patrimonial right, not its social dimension, characterizes it. This article deals with the differences between subjective law and legitimate interest in the application of urban norms.

Keywords: Licensing; Administration; Building.

\footnotetext{
* Doutor em Direito Civil pela Universidade do Estado do Rio de Janeiro - UERJ (2005), Doutor em Ciências Ambientais e Florestais pela Universidade Federal Rural do Rio de Janeiro - UFRRJ (2015), Professor na Universidade Federal do Estado do Rio de Janeiro - UNIRIO e Desembargador no Tribunal Regional da 2a Região (Rio de Janeiro e Espírito Santo).
} 


\section{INTRODUÇÃO}

As marcas essenciais do direito subjetivo são demasiadamente fáceis de determinar. Sob o plano normativo do Direito do Urbanismo, as observações relativas ao direito subjetivo são exatas e reais, pois há "ex manifesto" dois direitos vivos e operantes: o do proprietário urbano e o da Administração Pública (CASTRO AGUIAR, 1996; ANDRADE OLIVEIRA, 1982, p. 235).

O primeiro de natureza privada (um direito subjetivo privado) e o outro de natureza pública (um direito subjetivo público). ${ }^{1}$ Aquele de absterem-se todos (menos um: o proprietário) (PONTES DE MIRANDA, 1983), de impedir o uso, gozo, disposição e reivindicação do objeto; e este de exigir do proprietário que se subsuma às normas administrativas que Ihe são próprias (MEIRELLES, 1985).

Este artigo trata das diferenças entre direito subjetivo e interesse legítimo na aplicação das normas urbanísticas. Primeiramente tratará das normas urbanísticas e licenciamento; em seguida das normas administrativa e interesses particulares.

\section{NORMA URBANÍSTICA E LICENCIAMENTO}

O Direito do Urbanismo pode ser definido como o conjunto de regras concernentes à afetação de espaço e sua disposição (MORAND-DEVILLER, 1996, p. 3). Ele tem por objeto o urbanismo como realidade, como problema e como solução (GARCIA DE ENTERRIA, 1979, p. 4). É caracterizado por ser um direito empírico, complexo e patrimonial, no qual sobreleva a sua dimensão social (MORANDDEVILLER, 1996, p. 4). ${ }^{2}$ Sobre ele recaem as mais variadas manifestações econômicas, financeiras, sociológicas e, sobretudo, humana (MORAND-DEVILLER, 1996, p. 3). Seu espectro de atuação é tal que se comunica com um dos mais novos ramos do Direito: o ambiental (MORAND-DEVILLER, 1996, p. 3). Tal consideração conduziu à elaboração de um caráter "para-ambiental" para o Direito do Urbanismo

\footnotetext{
${ }^{1}$ Sobre os direitos subjetivos públicos dedicamos o $\S 3^{\circ}$ da Parte XI. Os textos mais importantes sobre o assunto são os de Jellinek (1912) e de Santi Romano (2008). Todos os demais trabalhos constituem desdobramentos teóricos dessas duas obras.

${ }^{2}$ Cf. Tepedino (1999, p. 267) sobre propriedade e função social.
} 
(CONDESSO, 1999, p. 77). A célula de seu corpo é, geralmente, feita por uma figura: a construção (ROTHER, 1990, p. 194).

A práxis do Direito $^{3}$ reconheceu que as construções se sujeitam à observância de normas técnicas a que se convencionou chamar de urbanísticas (SILVA, 1981). Observa-se, normalmente, durante uma construção (até mesmo a direta pelo proprietário), a prática corrente e moente na nossa tradição jurídica do respeito às, hoje, anacrônicas) ${ }^{4}$ "posturas municipais" e que, na atualidade, pela nova ordenação constitucional, são classificadas de leis, especialmente aquelas editadas pelos municípios (CRETELLA JúNIOR, 1975, p. 53).

O fenômeno da experiência nos introduz, em uma dupla dimensão de visada, a sua face exterior e a sua face interior, seja pelo convencimento do homo urbanus, seja pelas ações naturalissimamente consideradas (MEIRELLES, 1985; SILVA, 1981). A experiência se concretiza no espaço de tempo e, se uma dada tomada individual pode ter impacto determinante, constitui por ela mesma o início de uma perspectiva, e disso são exemplos as transformações ocorridas nas cidades (SARNO, 2004, p. 7).

A experiência se concretiza no espaço de tempo e, se um dado da praxis individual pode ter um impacto determinante, constitui por ele mesmo a demonstração mais viva da sujeição do terrível direito de propriedade ao sistema de proteção dos interesses qualificados. ${ }^{5}$

A todos os ângulos resulta bem claro que a propriedade, como direito e como garantia, ${ }^{6}$ encontra na Constituição da República sustentação e amparo, e se na Carta Magna o direito é disciplinado, é nas leis, especialmente as municipais, que resulta o mais importante regime das limitações à propriedade (HAYEM, 1910, p. 326; FRAGOLA, 1919, p. 114). De maneira que se encontra no ordenamento jurídico infraconstitucional a maior extensão das formas de limitação, calcadas na ideia geral de que são dirigidas ao exercício do direito e não do próprio direito (LIMA, 1964, p. 103). Algo, aliás, que a Constituição preocupou-se de assegurar e criou, ela mesma,

\footnotetext{
${ }^{3}$ A concepção de praxis foi extraída de Capozzi (1996).

${ }^{4}$ A despeito da redação do art. 934, III, do Código de Processo Civil (BRASIL, 2015).

5 "Terrível" por empréstimo de obra de Rodotá, (1981, p. 399).

${ }^{6}$ Sobre a propriedade como um direito e como uma garantia cf. Grisel (1975, p. 358). 
o próprio desenho normativo do direito de propriedade ou, como mais modernamente se entende, das propriedades. ${ }^{7}$

A anulação de licença de construção, indevidamente outorgada ao proprietário da obra, é pressuposto da condenação no desfazimento de uma dada edificação ou da vedação do seu prosseguimento. ${ }^{8}$ Se a propriedade no seu conteúdo abrange a faculdade de construir, ${ }^{9}$ tal edificação somente pode ser objetada, se a atividade já não mais encontrar fundamento em ato consensual da Administração Pública que o valide e o reconheça como lícito (FIGUEIREDO, 1980).

As esferas de atuações conceituais das licitudes civis e administrativas devem ser sucessivamente consideradas e destinadas a um só intento lógico, porque não se compreende que possa ser a licença ilícita e a atividade civil dela resultante lícita (SUNDFELD, 1993). O interesse legítimo é fundamento da anulação da licença na relação do seu titular com a Administração Pública e da condenação do proprietário recalcitrante (MOREIRA NETO, 2005). O primeiro interesse é de natureza pública e dirigido ao Estado e o segundo de natureza privada e dirigido ao particular (MIRANDA, 2000).

\section{NORMA ADMINISTRATIVA E INTERESSES PARTICULARES}

O número de proposições particulares que podemos deduzir de uma fórmula concreta de direito subjetivo, se somente do interesse protegido que ele encerra, pode restar objetivamente indefinido no interesse legítimo.

Os métodos tradicionais de estudo e formação dos conceitos dividem-se em dois grupos: o público e o privado. Ambos foram amplamente analisados e classificados como sendo antitéticos. De maneira que tal distinção não deve ser identificada como uma barreira à sua aplicação (GASPARE, 1992, p. 12).

A formação de conceitos é o resultado de uma atividade complexa, em que todas as funções intelectuais básicas tomam parte (VIGOTSKI, 2003, p. 72-73). Sob certo ângulo de visada, toda atividade cognitiva e científica é voltada à formação de conceitos (DELEUZE; GUATTARI, 1997, p. 13). Não só criar conceitos, mas criar

\footnotetext{
7 Propriedade e propriedades cf. Pugliatti (1964, p. 145) e Barcelona (1996, p. 280).

${ }^{8}$ Por meio de embargo de obra nova.

${ }^{9}$ E não direito como dizem o código de 1916 e o de 2002.
} 
sempre conceitos novos é o objeto do conhecimento científico (DELEUZE; GUATTARI, 1997, p. 13). Paralelamente, deve o estudioso desconfiar dos conceitos, pois sem tal desconfiança a superação de problemas conceituais jamais ocorreria (DELEUZE; GUATTARI, 1997, p. 4).

Sob a perspectiva conceitual, uma norma administrativa deve tutelar um interesse público associado ao órgão cuja observância se estabelece. Entretanto, a indagação central aqui seria: haveria algum interesse particular tutelado em um sistema de proteção dos interesses públicos? A perplexidade é fundada e sobreleva se a resposta for positiva, como de fato o será, pois nenhum interesse é integralmente público em uma norma administrativa. Ao contrário, pode-se dizer que é preponderante. Em consequência, existiriam interesses particulares que estariam também sob tutela. A esses é que se quer proteger direta ou indiretamente, tipicamente ou não, ou seja: como direito subjetivo e interesse legítimo.

\section{CONSIDERAÇÕES FINAIS}

A tutela jurídica por normas administrativas de interesses particulares é, inicialmente, uma contradictio in terminis: a tutela é pública e é incompatível com a proteção de interesses particulares. A exigência protetiva que se manifesta em todo Estado de Direito é, de fato, o fundamento de sua explicação (VIRGA, 1966. p. 4). De maneira que atribuir ao particular poderes de cariz próprio, como direito subjetivo, em uma norma administrativa, constitui mais a sua afirmação como norma para toda a Administração Pública, do que um particular sistema unilateral de regramento da atividade pública. É nessa esteira que segue o interesse legítimo.

\section{REFERÊNCIAS}

ANDRADE OLIVERA, Fernando. As limitações da propriedade privada. Rio de Janeiro: Forense, 1982.

BARCELONA, Pietro. Diritto Privato e Società Moderna, Nápoles: Jovene, 1996.

BRASIL. Lei no 13.105, de 16 de março de 2015. Código de Processo Civil. Brasília, DF: Presidência da República, 2015. Disponível em: 
http://www.planalto.gov.br/ccivil_03/_ato2015-2018/2015/lei/l13105.htm. Acesso em: 20 jul. 2019.

CAPOZZI, Gino. Filosofia, Scienza e Praxis del Diritto. 3. ed. Nápoles: Jovene, 1996.

CASTRO AGUIAR, J. A. Direito da cidade. Rio de Janeiro: Renovar, 1996.

CONDESSO, Fernando. Direito do urbanismo noções fundamentais. Lisbora: Quid Juris, 1999.

CRETELLA JÚNIOR, José. Direito municipal, São Paulo: Leud, 1975.

DELEUZE, Gilles; GUATTARI, Félix. O que é Filosofia? 2. ed. Tradução: Bento Prado Jr e Alberto Alonso Munõz. São Paulo: Editora 34, 1997.

FIGUEIREDO, Luica Vale. Disciplina urbanística da propriedade. São Paulo: RT, 1980.

FRAGOLA, Giuseppe. Teoria delle limitazione amministrative al diritto a proprietà com speciale riferimento nei regolamenti comunali. Milão: Società Editrice Libreria, 1919.

GARCIA DE ENTERRIA, Eduardo. Lecciones de drecho urbanístico. Madri: Civitas, 1979.

GASPARE, Giuseppe di. Il potere nel diritto pubblico. Pádua: Cedam, 1992.

GRISEL, André. Droit Administrativ Suisse. Neuchatel: Editions Ides et Calendes, 1975.

HAYEM, Henri. Essai sur le Droit de Propriete et ses limites, Paris: Arthur Rousseau Editeurs, 1910.

JELLINEK, George. Sistema dei diritti pubblici subbiettivi. Traduação: V.E. Orlando. Milano: Società Editrice Libraria, 1912.

LIMA, Ruy Cirne. Princípios de Direito Administrativo. Porto Alegre: Sulina, 1964.

MEIRELLES, Hely Lopes. Direito municipal brasileiro. 5 ed. São Paulo: RT, 1985.

MIRANDA, Jorge. Manual de Direito Constitucional. Coimbra: Coimbra, 2000. v. 1.

MORAND-DEVILLER, J. Droit de I'urbanisme. Paris: Estem, 1996. 
MOREIRA NETO, Diogo de Figueiredo. Curso de Direito Administrativo. 14. ed. Rio de Janeiro: Forense, 2005.

PONTES DE MIRANDA, F. C. Tratado de direito privado. 4. ed. São Paulo: RT, 1983.

PUGLIATTI, Salvatore. La proprietà nel nuovo Diritto, Milão: Giuffrè, 1964.

RODOTÁ, Stefano. Il terribile diritto: studi sulla proprietà privata. Bolonha: Il Mulino, 1981.

ROMANO, Santi. 0 ordenamento jurídico. Tradução: Arno Dal Ri Júnior. Florianópolis: Fundação Boiteux, 2008.

ROTHER, Hans. Derecho urbanístico colombiano. Bogotá: Temis, 1990.

SARNO, Daniela Campos Libório de. Elementos de direito urbanístico. São Paulo: Manole, 2004.

SILVA, José Afonso da. Direito urbanístico brasileiro. São Paulo: Rt, 1981.

SUNDFELD, Carlos Ari. Licenças e autorizações no direito administrativo. Revista Trimestral de Direito Público, São Paulo, v. 3, p. 66-72, 1993.

TEPEDINO, Gustavo. Contornos constitucionais da propriedade privada in temas de direito civil. Rio de Janeiro: Renovar, 1999.

VIGOTSKI, Lev Semyonovitch. Pensamento e linguagem. Tradução: Jefferson Luiz Camargo. São Paulo: Martins Fontes, 2003.

VIRGA, Pietro. La tutela giurisdizionale nei confronti della pubblica ammnistrazioni, Milão: Giuffrè, 1966. 